\title{
The Ross procedure with a bicuspid pulmonary autograft
}

\author{
Fadi Hage", Ali Hage", Linrui Guo, Michael W. A. Chu \\ Division of Cardiac Surgery, Department of Surgery, Western University, London Health Sciences Centre, London, ON, Canada \\ \#These authors contributed equally to this work and are co-first authors. \\ Correspondence to: Dr. Michael W. A. Chu, MD, FRCSC. Professor of Surgery, B6-106 University Hospital, London Health Sciences Centre, 339 \\ Windermere Road, London, Ontario N6A 5A5, Canada. Email: michael.chu@lhsc.on.ca.
}

Submitted Aug 31, 2020. Accepted for publication May 10, 2021.

doi: $10.21037 /$ acs-2020-rp-14

View this article at: http://dx.doi.org/10.21037/acs-2020-rp-14

\section{Clinical vignette}

A twenty-four-year-old male with a history of hypertension and bicuspid aortic valve (BAV), presented with a oneyear history of decreasing exercise tolerance and NYHA class II symptoms. Transthoracic echocardiography (TTE) demonstrated mild aortic stenosis with mean and peak gradients of 20 and $37 \mathrm{mmHg}$, respectively, and severe aortic insufficiency. The aortic cusps were quite dysplastic with areas of fibrosis and calcification. The pulmonary valve was functioning well with mild insufficiency. Left ventricular (LV) ejection fraction was $55 \%$ with severely dilated $\mathrm{LV}$ dimensions with end-systolic and end-diastolic diameters of 44 and $73 \mathrm{~mm}$, respectively. Cardiac magnetic resonance imaging (MRI) suggested a dilated aortic annulus measuring $32 \mathrm{~mm} \times 28 \mathrm{~mm}$ with a well-matched pulmonary root. Surgical options were discussed, and the planned preference was for aortic valve (AV) repair, and Ross procedure as backup considering his young age and reluctance to take warfarin.

\section{Surgical techniques}

\section{Aortic root preparation}

A midline sternotomy and central cannulation were employed. The aortic root and ascending aorta were skeletonized and a transverse aortotomy made just above the level of the sinotubular junction, allowing for antegrade cold Del Nido cardioplegia delivery. The AV was carefully examined revealing a dysplastic and mildly calcified unicuspid valve. We contemplated a bicuspidization repair strategy, but felt the anatomy was not ideal and that a pulmonary autograft would provide better long-term function and durability. Thus, the AV was excised en bloc and the annulus thoroughly debrided. We scalloped out the left and right main coronary buttons and placed direct ostial catheters within them. We preserved the non-coronary sinus and the bridge of aortic wall between the left/right sinus to be later incorporated into the anastomosis with the ascending aorta to provide external support for the pulmonary autograft.

\section{Pulmonary autograft harvesting}

The pulmonary artery was incised at its bifurcation and reflected anteriorly. Assessment of the pulmonary autograft identified a bicuspid pulmonary valve, Sievers type 1 morphology with two well-developed commissures and one raphe in the conjoint cusp. Nonetheless, the pulmonary cusps were pliable, without significant fenestrations and geometric heights of $20 \mathrm{~mm}$ each, making repair suitable.

The pulmonary autograft was harvested by inserting a right-angled forceps at the base of the anterior commissure and the pulmonary infundibulum incised $5 \mathrm{~mm}$ below the valve. Caution was taken in the posterior dissection, to avoid coronary injury. The pulmonary autograft was incised with a deep posterior commissure to match the well-developed posterior commissure in the unicuspid aortic annulus, and left the anterior portion of the pulmonary autograft largely planar to match the anterior planar shape of the unicuspid annulus.

\section{Pulmonary autograft implantation: proximal} anastomosis and aortic annuloplasty

A subannular row of six non-pledgetted, 2-0 Ethibond 
sutures were passed through the LV outflow tract (LVOT) to the exterior aspect of the aortic root. The autograft was implanted as a total root in a subannular position using interrupted 4-0 polypropylene sutures. This was achieved by placing suture bites $3-4 \mathrm{~mm}$ deep to the aortic annulus in the LVOT and on the pulmonary autograft, penetrating the suture $1 \mathrm{~mm}$ deep to the insertion of the cusp and exiting the suture $2-3 \mathrm{~mm}$ above the cusp insertion on the exterior aspect of the pulmonary autograft. We believe this technique ensures the pulmonary autograft will be implanted symmetrically deep within the LVOT and that the infundibular muscle is completely excluded, which is important for valvular competence. In this case, the pulmonary autograft was implanted with the commissures at 180 degrees from each other, with each cusp subtending $50 \%$ of the unicuspid aortic annulus.

Using the Schaefers repair caliper, we measured an effective height of $10 \mathrm{~mm}$ for the non-conjoint cusp and a prolapsing conjoint cusp; therefore, the conjoint cusp was centrally plicated with two 6-0 polypropylene sutures to achieve an effective height of $10 \mathrm{~mm}$.

We returned our attention to the previously placed subannular Ethibond sutures and passed them through the base of a $30 \mathrm{~mm}$ straight Dacron ring graft to complete the extra-aortic annuloplasty. We routinely perform an external aortic annuloplasty for annular diameters of $27 \mathrm{~mm}$ or greater or significant aortic regurgitation to prevent late dilatation. Coronary buttons were reimplanted and excess pulmonary autograft trimmed.

\section{Pulmonary homograft implantation and distal autograft anastomosis}

The CryoLife SynerGraft $30 \mathrm{~mm}$ pulmonary homograft was trimmed distally and anastomosed to the pulmonary bifurcation using two running 5-0 polypropylene sutures. The proximal anastomosis to the right ventricle outflow tract was completed with running 4-0 polypropylene suture.

The pulmonary autograft was anastomosed to the ascending aorta with running 5-0 polypropylene suture, respecting the commissural orientation at 180 degrees to preserve autograft symmetry.

The patient was extubated the evening of surgery and transferred to the ward on the first postoperative day, where he recovered without complications allowing for his discharge home on the sixth postoperative day. At one-year follow-up, he was completely asymptomatic and ambulating without limitations. Repeat TTE revealed a normal functioning pulmonary autograft with no aortic insufficiency, normally functioning pulmonary homograft, and preserved LV function.

\section{Comment}

Although it could be argued to have simply replaced our patient's AV with a standard valve prosthesis, his young age posed a challenge with his longer anticipated life expectancy and higher cumulative risk of prosthesisrelated complications. The Ross procedure, unlike standard bioprosthetic or mechanical AV replacement, restores expected survival equivalent to that of age and gendermatched general population (1).

A bicuspid pulmonary valve is considered a rare congenital anomaly with an estimated incidence of $0.1 \%$ and may be considered a relative contraindication for the Ross procedure (2). However, our patient had favourable bicuspid anatomic characteristics with pliable cusps, good commissural orientation, and geometric height of $20 \mathrm{~mm}$, and we applied all the principles of BAV repair with symmetric commissural implantation, a tailored aortic annuloplasty and achieving an effective height of $10 \mathrm{~mm}$ to ensure a well-functioning bicuspid pulmonary autograft. We have employed this technique successfully in two patients. To our knowledge, only one previous paper presented a repair of a bicuspid pulmonary autograft valve, but this was for moderate aortic insufficiency noted five days after the Ross procedure (3). In this report, we present the concomitant repair of a bicuspid pulmonary autograft at the time of the index operation. We aim at drawing on the advantages of the Ross procedure for young patients while restoring the function of the bicuspid pulmonary autograft using common BAV repair techniques, thus extending the use of the Ross procedure to more patients who would otherwise be considered ineligible.

\section{Acknowledgments}

Funding: None.

\section{Footnote}

Conflicts of Interest: MWAC has received speaker's honorarium 
from Medtronic, Edwards Lifesciences, Terumo Aortic, Abbott Vascular and Boston Scientific. The other authors have no conflicts of interest to declare.

Open Access Statement: This is an Open Access article distributed in accordance with the Creative Commons Attribution-NonCommercial-NoDerivs 4.0 International License (CC BY-NC-ND 4.0), which permits the noncommercial replication and distribution of the article with the strict proviso that no changes or edits are made and the original work is properly cited (including links to both the formal publication through the relevant DOI and the license). See: https://creativecommons.org/licenses/by-nc-nd/4.0/.

Cite this article as: Hage F, Hage A, Guo L, Chu MWA. The Ross procedure with a bicuspid pulmonary autograft. Ann Cardiothorac Surg 2021;10(4):552-554. doi: 10.21037/acs-2020rp-14

\section{References}

1. Mazine A, El-Hamamsy I, Verma S, et al. Ross Procedure in Adults for Cardiologists and Cardiac Surgeons: JACC State-of-the-Art Review. J Am Coll Cardiol 2018;72:2761-77.

2. Jashari R, Van Hoeck B, Goffin Y, et al. The incidence of congenital bicuspid or bileaflet and quadricuspid or quadrileaflet arterial valves in 3,861 donor hearts in the European Homograft Bank. J Heart Valve Dis 2009;18:337-44.

3. Vistarini N, Gebhard C, Desjardins G, et al. Successful Repair of a Bicuspid Pulmonary Autograft Valve Causing Early Insufficiency After a Ross Procedure. Ann Thorac Surg 2016;101:e99-101. 